\title{
The Int7G24A variant of transforming growth factor-beta receptor type $I$ is a risk factor for colorectal cancer in the male Spanish population: a case-control study
}

\author{
Adela Castillejo ${ }^{\dagger 1}$, Trinidad Mata-Balaguer ${ }^{\dagger 1}$, Carla Guarinos ${ }^{1}$, María- \\ Isabel Castillejo ${ }^{1}$, Ana Martínez-Cantó ${ }^{1}$, Víctor-Manuel Barberá1,2, \\ Paola Montenegro1, Enrique Ochoa ${ }^{3}$, Rafael Lázaro ${ }^{4}$, Carmen Guillén- \\ Ponce $^{2}$, Alfredo Carrato ${ }^{1}$ and José-Luís Soto*1,2
}

\begin{abstract}
Address: ${ }^{1}$ Molecular Oncology Group, Elche University Hospital, Camino Almazara 11, 03203 Elche, Spain, ${ }^{2}$ Genetic Counseling in Cancer Unit, Elche University Hospital, Camino Almazara 11, 03203 Elche, Spain, ${ }^{3}$ Molecular Biopathology Department, Castellon Provincial Hospital. Avenida Doctor Clara 19, 12002 Castellon de La Plana, Spain and ${ }^{4}$ Pathology Department, La Plana Hospital, Partida Carinyena Km 0.5, 12540 Vila-real, Spain

Email: Adela Castillejo - acastillejo@umh.es; Trinidad Mata-Balaguer - trini_mata@hotmail.com; Carla Guarinos - carlaguarinos@gmail.com; María-Isabel Castillejo - micastillejo@gmail.com; Ana Martínez-Cantó - martinez_anacan@gva.es; Víctor-

Manuel Barberá - barbera_vicjua@gva.es; Paola Montenegro - paolacmb@yahoo.es; Enrique Ochoa - enrique.ochoa@hospital2000.net; Rafael Lázaro - lazaro_raf@gva.es; Carmen Guillén-Ponce - carmenguillenponce@yahoo.es; Alfredo Carrato - acarrato@telefonica.net; JoséLuís Soto* - jlsoto@umh.es

* Corresponding author †Equal contributors
\end{abstract}

Published: 20 November 2009

BMC Cancer 2009, 9:406 doi:10.1 186/147/-2407-9-406
Received: 10 June 2009

Accepted: 20 November 2009

This article is available from: http://www.biomedcentral.com//47/-2407/9/406

(C) 2009 Castillejo et al; licensee BioMed Central Ltd.

This is an Open Access article distributed under the terms of the Creative Commons Attribution License (http://creativecommons.org/licenses/by/2.0), which permits unrestricted use, distribution, and reproduction in any medium, provided the original work is properly cited.

\begin{abstract}
Background: The Int7G24A variant of transforming growth factor-beta receptor type I (TGFBRI) has been shown to increase the risk for kidney, ovarian, bladder, lung and breast cancers. Its role in colorectal cancer (CRC) has not been established. The aims of this study were to assess the association of TGFBRI*Int7G24A variant with CRC occurrence, patient age, gender, tumour location and stage.

Methods: We performed a case-control study with 504 cases of sporadic CRC; and 504 noncancerous age, gender and ethnically matched controls. Genotyping analysis was performed using allelic discrimination assay by real time PCR.

Results: The Int7G24A variant was associated with increased CRC incidence in an additive model of inheritance $(P$ for trend $=0.005)$. No significant differences were found between Int7G24A genotypes and tumour location or stage. Interestingly, the association of the Int7G24A variant with CRC risk was significant in men (odds ratio 4.10 with $95 \%$ confidence intervals 1.4 I-II.85 for homozygous individuals; $P$ for trend $=0.00023$ ), but not in women. We also observed an increase in susceptibility to $C R C$ for individuals aged less than 70 years.
\end{abstract}

Conclusion: Our data suggest that the Int7G24A variant represents a risk factor for CRC in the male Spanish population. 


\section{Background}

Transforming growth factor beta (TGF- $\beta$ ) is one of the most potent inhibitors of proliferation in epithelial, neuronal and hematopoietic cells. The effects of an activated TGF- $\beta$ signalling pathway include inhibition of cell cycle progression, promotion of terminal differentiation and activation of cell death [1].

TGF- $\beta$ receptor type I (encoded by TGFBR 1 ) is a mediator of TGF- $\beta$ growth inhibitory signals. Extracellular TGF- $\beta$ binds first to the type II receptor, which then dimerizes and activates the type I receptor, sending the signal to the nucleus via SMAD proteins [1]. Abnormalities of this signalling pathway are almost universal in cancer cells through a variety of mechanisms [2]. Among them are overexpression of the ligands, downregulation of receptors, and point mutations and deletions in the genes coding for proteins involved in the pathway [3]. Different TGFBR1 allelic variants have been associated with susceptibility to develop different types of tumours. Thus, the TGFBR $1{ }^{*} 6$ A allele, located at exon 1 (rs11466445) has been shown to be a susceptibility allele for colorectal cancer (CRC), breast and ovarian cancers, based on a metaanalysis of many case-control studies [4]. In contrast, one recent report found a lack of an association between this variant and CRC risk $[5,6]$. The role of this variant in CRC susceptibility remains controversial.

The TGFBR1_Int7G24A polymorphism (rs334354; NM_004612.2:c.1255+24G>A) has also been associated with cancer risk, but the function of this variant has yet to be discovered. Individuals carrying the Int7G24A variant have an increased risk of developing non-small cell lung cancer, renal cell carcinomas, transitional cell carcinomas of the bladder, and breast cancer [7-10]. To our knowledge, there is only one published report on the association between this genetic variant and CRC [11]. In that study, there was no evidence of an association between this polymorphism and colorectal cancer risk in familial cases.

To test whether the Int7G24A variant might be associated with the incidence of CRC in the Spanish population, we carried out a case-control study with 504 cases and 504 matched controls for age, gender and ethnicity. We found a significant association of the Int7G24A variant with the incidence of CRC. It also showed significant associations with patient gender (male) and age, but not with tumour location or stage. These data support the hypothesis that Int7G24A variant may be a low penetrance tumour susceptibility allele that predisposes to CRC mainly in men in the Spanish population.

\section{Methods}

\section{Study subjects}

A total of 504 sporadic cases of CRC and 504 controls from the Elche University Hospital and Castellon Provin- cial Hospital tissue banks were analysed in this study. Written consent was obtained from every patient to be included in the respective tissue banks. Patients diagnosed with a familial cancer syndrome were excluded. Thus, patients with Amsterdam II criteria for hereditary nonpolyposis colorectal cancer were excluded, as were patients with Bethesda criteria and who were negative for microsatellite instability, who were studied in our genetic counselling unit.

This was a hospital-based case-control study. Controls were selected from the same hospitals with no personal history of cancer and selected according to diagnoses unrelated to the disease of interest. They were matched for age, gender and race/ethnicity with the study patients. The study was approved by the Ethics Committees from the Elche University and Castellon Provincial hospitals.

The median age for patients with CRC at diagnosis was 70 years (range 23-92); for controls it was 72 years (range 2398). Gender distribution for the patients with CRC ('cases') was $59.4 \%$ men and $40.6 \%$ women; for controls, it was $53.3 \%$ and $46.7 \%$, respectively. In $33.3 \%$ of the cases, tumours were in the proximal colon and $66.7 \%$ were located at the distal colon and rectum; $45 \%$ were classified as low stage (I and II) and 55\% as high stage (III and IV). The numbers of cases and controls for whom information was unavailable for stratification were 64 and one, respectively.

\section{DNA and RNA isolation and CDNA synthesis}

Control DNA samples were obtained from peripheral blood samples. DNA samples from cases were isolated after mechanical homogenization of non-cancerous frozen colorectal tissue. DNA isolation was performed using an EZ1 BioRobot (Qiagen, Valencia, CA, USA) according to the manufacturer's instructions. RNA was isolated from normal colon tissue of selected cases in the same manner. Synthesis of cDNA was performed using random primers and Reverse Transcription reagents (Applied Biosystems, Foster City, CA, USA).

\section{Genotyping the Int7G24A polymorphism (rs334354)}

A total of 1008 individuals (504 cases and 504 controls) were analysed for this polymorphism. Single nucleotide polymorphism (SNP) analysis was performed using a real-time polymerase chain reaction (PCR) TaqMan assay for allelic discrimination (TaqMan SNP Genotyping Assay; ID: C_1413390_20; Applied Biosystems) with minor modifications. All PCR reactions contained $20 \mathrm{ng}$ DNA, $10 \mu \mathrm{L}$ TaqMan Universal Master Mix (Applied Biosystems), $0.5 \mu \mathrm{L}$ of the assay and water for a final volume of $20 \mu \mathrm{L}$. The appropriate negative controls were also run in parallel. Real time PCR was performed on an ABI Prism 7300 Sequence Detection System (Applied Biosystems) using the following conditions: $95^{\circ} \mathrm{C}$ for $10 \mathrm{~min}$ and 40 
cycles of amplification $\left(95^{\circ} \mathrm{C}\right.$ for $15 \mathrm{~s}$ and $60^{\circ} \mathrm{C}$ for 1 min). Software in the system was used to quantify the fluorescent signals from VIC- or FAM-labelled probes. Two representative cases for each genotype were sequenced directly to confirm the genotyping results. Sequencing reactions were performed using BigDye Terminator (version 3.1) Cycle Sequencing kits and run in an ABI Prism 3100-Avant Genetic Analyser (Applied Biosystems).

\section{Analysis of the lengths of Int7G24 and Int7A24 variant transcripts}

Four cases previously genotyped as $G / G$ and four genotyped as $A / A$ were analysed to compare the length of their TGFBR1 transcripts. This experiment was performed using PCR and capillary electrophoresis. Primer sequences designated IVS7cDNA-F (labelled with 6-FAM) were 5'AAATTGCTCGACGATGTTCC-3' for exon 7, and IVS7cDNA-R, 5'-CTCTGCCATCTGTTTGGGAT-3' for exon 8. The expected size of a normal PCR product was $151 \mathrm{bp}$. Twenty-five nanograms of DNA were used in a total PCR reaction volume of $25 \mu \mathrm{L}$ AmpliTaq Gold PCR Master Mix $2 \times$ (Applied Biosystems) and $20 \mathrm{pmol}$ of each primer. After an initial $9 \mathrm{~min}$ at $95^{\circ} \mathrm{C}$, PCR was run for 40 cycles of $95^{\circ} \mathrm{C}$ for $20 \mathrm{~s} ; 55^{\circ} \mathrm{C}$ for $20 \mathrm{~s}$ and $72^{\circ} \mathrm{C}$ for $20 \mathrm{~s}$; followed by $10 \mathrm{~min}$ final extension at $72^{\circ} \mathrm{C}$. Diluted $(1 / 10)$ PCR products along with Genescan 500 ROX size standards in HiDi formamide (Applied Biosystems,) were resolved by capillary electrophoresis (ABI 3100 Avant, Applied Biosystems) using POP6 polymer. GeneScan Software was used for the analysis of PCR fragment lengths (Applied Biosystems).

\section{Statistical analysis}

We first examined the Hardy-Weinberg equilibrium of allelic distribution separately for cases and controls and then compared the allele frequencies between cases and controls. We evaluated the association of Int7G24A genotypes with CRC using multivariate unconditional logistic regression models assuming dominant $(A / A$ and $G / A$, versus $G / G)$, additive $(G / G$ and $G / A$, versus $A / A)$ or recessive ( $A / A$, versus $G / G$ and $G / A$ ) modes of inheritance, respectively. In our basic models, we adjusted for age and gender. We explored the potential effects of modification by age in an analysis stratified by the cases' median age at diagnosis ( $\leq 70$ or $>70$ years). A $\chi^{2}$ test was used to evaluate the differences in Int7G24A variant carrier frequencies between tumour and control groups for the dominant and the recessive models and to analyse any association between the SNP and clinical and pathological factors. Armitage's trend test was used to calculate $P$ for trend in the additive model of inheritance. All $P$ values were twosided and $P<0.05$ was considered significant. Results are expressed as the odds ratio (OR) and 95\% confidence interval (CI).

\section{Results \\ Int7G24A genotyping}

Genotype distribution in the control and case populations did not deviate significantly from that expected for a population in Hardy-Weinberg equilibrium $(P>0.2)$. Allelic frequencies found in controls were 0.815 and 0.184 for the Int7G24 and Int7A24 alleles, respectively. For the patients with CRC, these frequencies were 0.764 and 0.236 , respectively. Genotyping of the Int7G24A polymorphism is shown in Figure 1. The crude ORs assuming dominant, additive and recessive models of inheritance showed a significant increase of CRC risk for individuals carrying the Int7G24A variant. The best-fit model of inheritance was the additive one ( $P$ for trend $=0.005$ ). Unconditional logistic regression adjusted for age, considering the median age for cases (70 y) as the threshold level, showed a statistically significant association of the Int7G24A variant with CRC susceptibility, for those individuals younger than 70 years $(P$ for trend $=0.004)$. No statistically significant association was found between this polymorphism and individuals aged over 70 years (Table 1).

The results after gender adjustment were clear-cut, with no CRC risk association found for women and a strong statistically significant association for the presence of the Int7G24A variant and CRC in men ( $P$ for trend = $0.00023)$. The ORs for heterozygous and homozygous individuals for the Int7G24A variant were 1.74 (95\% CI: 1.19-2.54) and 4.10 (95\% CI: 1.41-11.85), respectively (Table 1). No significant associations were found between different genotypes and tumour location or stage.

\section{Lengths of Int7G24 and Int7A24 transcripts}

We performed mRNA analysis from homozygous $G / G$ and $A / A$ individuals to test if the Int7G24A variant might be related to an abnormal mRNA splicing that could explain the function of this allele as a risk factor for CRC. However, the mRNA fragments obtained always had the expected size for normal mRNA splicing independently of the genotype.

\section{Discussion}

The TGF $\beta$ pathway plays an important role in tumour development and progression [1]. Recently, there has been interest in the contribution of genetic variation in this pathway to cancer susceptibility. Several polymorphic variants in genes involved in this pathway have been studied [12]. The TGFBR1_Int7G24A variant has been previously associated with cancer risk, but the role of this variant has yet to be discovered. Zhang et al [7] reported that homozygous but not heterozygous carriers of this variant have an increased risk of developing non-small cell lung cancer. Chen et al [9] reported the association of this 


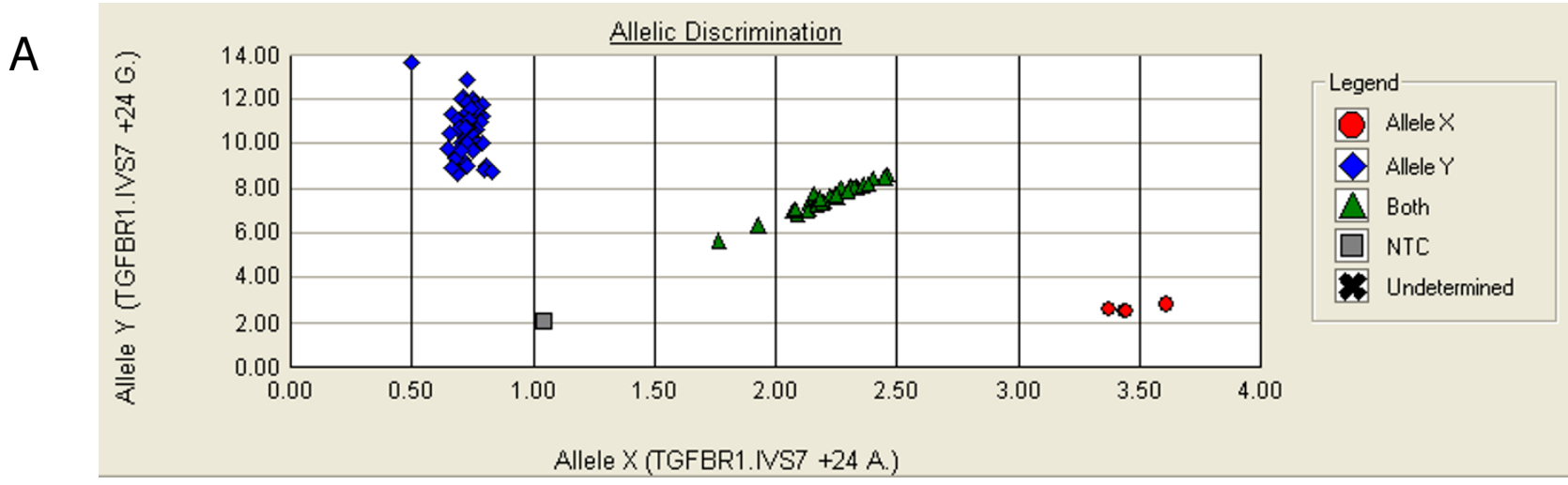

B
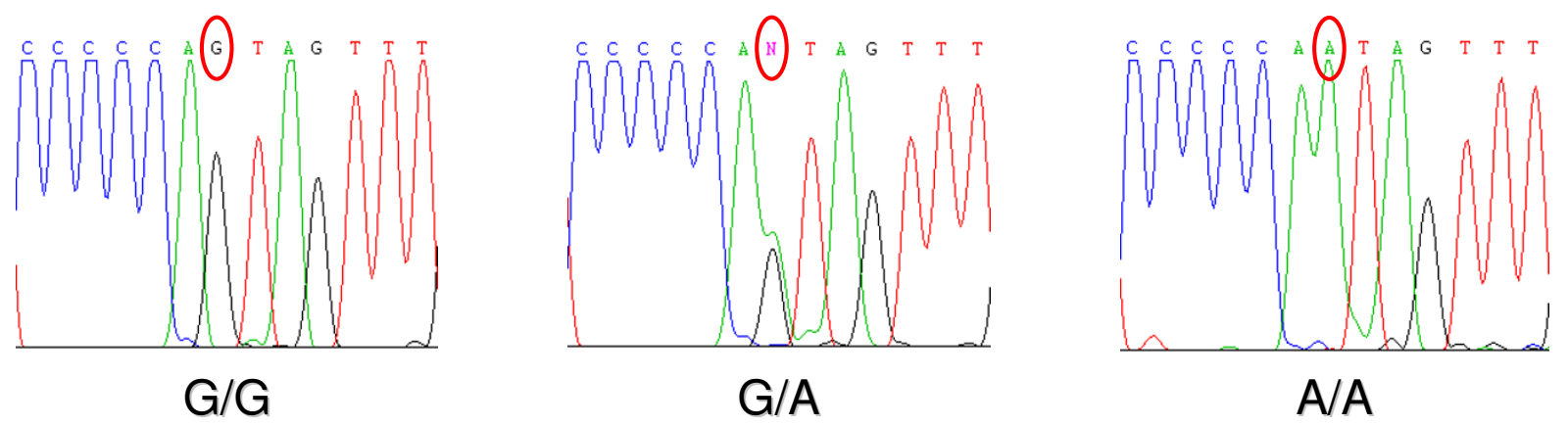

Figure I

Genotyping of the Int7G24G>A polymorphism. (A) Real-time PCR for allelic discrimination. (B) Direct sequencing to confirm the genotypes.

variant with the incidence of renal cell carcinomas (OR: 2.2; 95\% CI: 1.22-3.96) and transitional cell carcinoma of the bladder (OR: 2.45 ; 95\% CI: 1.8-3.16). In a meta-analysis of these three studies [8], the pooled OR was 1.76 (95\% CI: $1.33-2.34 ; P<0.0001)$. Another case-control study [10] found an association with breast cancer (OR: 2.42; 95\% CI: 1.55-3.79), suggesting that the Int7G24A variant could also represent a risk factor for invasive and metastatic breast cancers (OR: 2.61; 95\% CI: 1.65-4.11). Skoglund-Lundin et al. [11] did not detect a significant association between CRC risk and the Int7G24A variant when they analysed data from cases with a familial history of colorectal cancer. The expectedly low-penetrance effect of this putative susceptibility allele would be very difficult to detect in cases with high-penetrance alleles. Moreover, the authors did not stratify their data according to sex.

An exclusion criterion for the present study was the diagnosis of any familial cancer syndrome predisposing to CRC, such as hereditary non-polyposis colorectal cancer, familial adenomatous polyposis, Cowden disease and Peutz-Jeghers syndrome. We were interested to evaluate the effect of this SNP for sporadic CRC susceptibility and tumour progression. The potential effect of the SNP on familial syndromes as modifier of the penetrance, or the phenotype expression should be approached independently in further specific studies.

Control individuals were selected from those patients treated at an emergency department with diverse non-cancerous pathologies and with no personal history of cancer. The probability that controls suffered from diseases putatively caused by the same risk factors as the patients with CRC is extremely low.

It is well known that one of the main limitations and sources of confounding the results in association studies comes from population stratification and inappropriate sample sizes. A priori, our study with 504 sporadic cases and 504 controls allowed us to detect an OR of 1.5 for G/ $A$ heterozygous individuals (considering a frequency of 0.3 ) and an OR of 2.0 for $A / A$ homozygous individuals (considering a frequency of 0.025 ) with $80 \%$ power (twosided test, alpha level 5\%). Estimated genotype frequen- 
Table I: Genotypes of the Int7G24A polymorphism in cases and controls and their association with CRC.

\begin{tabular}{|c|c|c|c|c|}
\hline Int7G24A genotype & $\begin{array}{c}\text { Cases } \\
(n=504)\end{array}$ & $\begin{array}{l}\text { Controls } \\
(n=504)\end{array}$ & OR $[95 \% \mathrm{Cl}]$ & $p$ \\
\hline Dominant model & number (\%) & number (\%) & & \\
\hline G/G & $296(58.73)$ & $333(66.07)$ & I (ref) & \\
\hline$G / A$ and $A / A$ & 208 (4I.27) & I7| (33.93) & 1.37 [1.06-1.77] & $0.019 *$ \\
\hline \multicolumn{5}{|l|}{ Additive model } \\
\hline G/G & $296(58.73)$ & $333(66.07)$ & I (ref) & \\
\hline G/A & $178(35.32)$ & $156(30.95)$ & $1.28[0.98-1.67]$ & \\
\hline $\mathbf{A} / \mathbf{A}$ & $30(5.95)$ & $15(2.98)$ & $2.25[1.20-4.23]$ & $0.005 * *$ \\
\hline \multicolumn{5}{|l|}{ Recessive model } \\
\hline G/G and $\mathbf{G} / \mathbf{A}$ & $474(94.05)$ & $489(97.02)$ & I (ref) & \\
\hline \multirow[t]{2}{*}{ A/A } & $30(5.95)$ & $15(2.98)$ & $2.04[1.11-3.85]$ & $0.032 *$ \\
\hline & $\begin{array}{c}\leq 70 \text { yrs } \\
(n=213)\end{array}$ & $\begin{array}{c}\leq 70 \text { yrs } \\
(n=219)\end{array}$ & & \\
\hline G/G, number (\%) & II 8 (55.40) & $150(68.49)$ & I (ref) & \\
\hline G/A, number (\%) & $80(37.56)$ & $61(27.85)$ & $1.67[1.11-2.5 I]$ & \\
\hline \multirow[t]{2}{*}{ A/A, number (\%) } & $15(7.04)$ & $8(3.65)$ & $2.38[1.00-5.68]$ & $0.004 * *$ \\
\hline & $\begin{array}{c}>70 \text { yrs } \\
(n=227)\end{array}$ & $\begin{array}{c}>70 \text { yrs } \\
(n=284)\end{array}$ & & \\
\hline G/G, number (\%) & $145(63.88)$ & $182(64.08)$ & I (ref) & \\
\hline G/A, number (\%) & $72(31.72)$ & $95(33.45)$ & $0.95[0.65-1.39]$ & \\
\hline \multirow[t]{2}{*}{ A/A, number (\%) } & $10(4.4 I)$ & $7(2.46)$ & I.79 [0.69-4.67] & $0.662 * *$ \\
\hline & $\begin{array}{c}\text { males } \\
(n=295)\end{array}$ & $\begin{array}{c}\text { males } \\
(n=226)\end{array}$ & & \\
\hline G/G, number (\%) & $166(56.27)$ & $160(70.80)$ & I (ref) & \\
\hline G/A, number (\%) & I I 2 (37.97) & $62(27.43)$ & $1.74[1.19-2.54]$ & \\
\hline \multirow[t]{2}{*}{ A/A, number (\%) } & $17(5.76)$ & 4 (1.77) & $4.10[1.41-11.85]$ & $0.00023 * *$ \\
\hline & $\begin{array}{l}\text { females } \\
(n=202)\end{array}$ & $\begin{array}{l}\text { females } \\
(n=277)\end{array}$ & & \\
\hline G/G, number (\%) & $126(62.38)$ & 172 (62.09) & I (ref) & \\
\hline G/A, number (\%) & $63(31.19)$ & $94(33.94)$ & $0.92[0.62-1.36]$ & \\
\hline A/A, number (\%) & $13(6.44)$ & II (3.97) & $1.61[0.71-3.65]$ & $0.688^{* *}$ \\
\hline
\end{tabular}

$* \chi^{2}$ test; ** $p$ for trend (Armitage's trend test)

cies were obtained as preliminary results in a subset of our control population and were similar to the frequencies registered at the SNP database for European populations http://www.ncbi.nlm.nih.gov/projects/SNP/. The results presented here show an increase of CRC susceptibility for those individuals carrying the Int7G24A variant allele with a dosage effect (additive model of inheritance). Adjusting the OR by age, we only observed an association of Int7G24A variant carriers with CRC risk in subjects aged less than 70 years (Table 1 ). Thus, the genetic risk effect is more evident in younger individuals. Ageing implies a huge amount of acquired predisposing carcinogenic factors that could overshadow the mild effect of the susceptibility alleles.

When we analysed the data adjusting by gender, we found that the Int7G24A variant was strongly associated with
CRC risk in men but not women. We do not know why. Evidence is accumulating supporting gender-related differences in the development of CRC, but to our knowledge, few reports have been published regarding sexspecific relationship between SNPs and CRC. Slattery et al [13] reported that the oestrogen receptor beta CA repeat polymorphism was associated with an increase relative risk of colon cancer in women but not in men. On the contrary, increasing number of CAG repeats in the androgen receptor was directly associated with colon cancer among men, but not in women. Both oestrogen and androgen receptors are present in colorectal tissue and it has been suggested that these might be important in regulating the CRC risk associated with these hormones. Activation of the TGF $\beta$ signal transduction system is also subject to hormonal regulation [14]. This striking connection might suggest the involvement of sex steroid hor- 
mones acting through the TGF $\beta$ pathway in the aetiology of CRC.

The apolipoprotein E (ApoE) epsilon 2/3 polymorphism is another example of gender-specific modulation of CRC risk and prognosis where men have a highly significant association but there is no association in women [15]. Bae et al [16] found a gender-specific association between polymorphisms of the gene for vascular endothelial growth factor (VEGF $936 C>T$ ) and CRC in the Korean population. T allele-bearing genotypes significantly increased the risk for CRC in women but not in men. Moreover, there are gender-related survival differences in association with EGFR (gene for epidermal growth factor receptor) polymorphisms in patients with metastatic colon cancers [17]. Again, oestrogens and androgens may be behind all these associations because of their functional links with ApoE [18], VEGF [19] and EGFR [20].

It is possible that the positive associations shown here were not based on real effects of this polymorphism, but rather reflect unknown differences in population ancestry between the case and control groups [21]. We consider the probability of false-positive inference attributable to population stratification to be small, because the cases and control individuals were recruited from an ethnically homogeneous population with no indication of a significant amount of recent genetic admixture.

Given our results and those in the literature, it seems reasonable to speculate that there might be a gender-dependent allelic architecture for CRC risk associated with sex steroids. This would introduce a new level of complexity in the 'common disease-common variant' hypothesis [22]. Our association studies between this polymorphism and clinicopathological factors did not show any statistically significant results. The lack of difference in genotype distribution between male and female patients with CRC might be attributed to the contribution and compensation of other gender-related susceptibility polymorphisms, where the risks affect women preferentially. To date, how this intronic SNP affects oncogenesis remains to be elucidated. It has been proposed that this SNP creates an alternative splice site within intron 7 . In vitro analysis with breast and ovarian cell lines from carriers of the Int7G24A variant have shown the retention of the seventh intron in the mRNA up to the site of the Int7G24A variant [23]. We wanted to study if this alternative splicing also occurred in the normal colorectal tissue from patients with CRC. However, we concluded that factors other than alternative splicing might account for the association of this polymorphism with cancer, although we cannot rule out the possibility that Int7G24A variant is a marker rep- resenting a TGFBR1 haplotype. In this regard, it is interesting to note the likely 'bystander susceptibility effect' for the TGFBR $1{ }^{*} 6$ A allele because of linkage disequilibrium with the unknown causative mutation of the allele-specific expression (ASE) in the TGFBR1 gene [24]. In our series, no linkage disequilibrium was found between the TGFBR1 ${ }^{*} 6 A$ and Int7G24A variant (unpublished results). No information is available regarding the association between variant and ASE. Further studies are required to characterize the molecular mechanisms by which variant is involved in gender-specific susceptibility to CRC.

\section{Conclusion}

The results of the present study strongly suggest that the TGFBR1_Int7G24A allele does confer an increased risk of colorectal cancer in the male Spanish population. The growing list of gender-dependent association of allelic variants and the risk of colorectal cancer might suggest the involvement of sex steroid hormones in the aetiology of CRC.

\section{Competing interests}

The authors declare that they have no competing interests.

\section{Authors' contributions}

AC participated in its design and coordination, in the molecular genetic studies and helped to draft the manuscript. TM-B, CG, M-IC, AM-C, V-MB participated in the molecular genetic studies and helped to draft the manuscript. PM participated in the design of the study, performed the statistical analysis and helped to draft the manuscript. EO, RL participated in samples biobanking and helped to draft the manuscript. CG-P, AC participated in the design of the study and performed the statistical analysis. J-LS conceived of the study, and participated in its design and coordination and drafted the manuscript. All authors read and approved the final manuscript.

\section{Acknowledgements}

This action has been performed within the cooperation framework established by the Transversal Cancer Action approved by the Council of Ministers on October II th 2007 in accordance with the agreement between The Carlos III Health Institute (ISCIII), which is an autonomous entity currently belonging to the Ministry of Science and Innovation, and the Biomedical Research Foundation from the Hospital of Elche. Research supported in part by grants from the Generalitat Valenciana in Spain (API06/06) and the Biomedical Research Foundation from the Hospital of Elche, Spain (FIBElx02/2007). T.M-B is recipient of a fellowship from the Spanish Society of Medical Oncology (SEOM).

\section{References}

I. Siegel PM, Massagué J: Cytostatic and apoptotic actions of TGFbeta in homeostasis and cancer. Nat Rev Cancer 2003, 3(I I):807-82I.

2. Bian Y, Kaklamani V, Reich J, Pasche B: TGF-beta signaling alterations in cancer. Cancer Treat Res 2003, I I 5:73-94. 
3. Massagué J, Blain SW, Lo RS: TGFbeta signaling in growth control, cancer, and heritable disorders. Cell 2000, 103(2):295-309.

4. Pasche B, Kaklamani V, Hou N, Young T, Rademaker A, Peterlongo P, Ellis N, Offit K, Caldes T, Reiss M, Zheng T: TGFBRI*6A and cancer: a meta-analysis of $\mathbf{I} 2$ case-control studies. J Clin Oncol 2004, 22(4):756-758.

5. Skoglund J, Song B, Dalén J, Dedorson S, Edler D, Hjern F, Holm J, Lenander C, Lindforss U, Lundqvist N, Olivecrona H, Olsson L, Påhlman L, Rutegård J, Smedh K, Törnqvist A, Houlston RS, Lindblom A: Lack of an association between the TGFBRI*6A variant and colorectal cancer risk. Clin Cancer Res 2007, I 3( I 2):3748-3752.

6. Castillejo A, Mata-Balaguer T, Montenegro P, Ochoa E, Lázaro R, Martínez-Cantó A, Castillejo MI, Guarinos C, Barberá VM, GuillénPonce C, Carrato A, Soto JL: The TGFBRI*6A allele is not associated with susceptibility to colorectal cancer in a Spanish population: a case-control study. BMC Cancer in press.

7. Zhang HT, Fei QY, Chen F, Qi QY, Zou W, Wang JC, Zhang RM, Tao $\mathrm{SH}$, Chen XF, Luo ZW: Mutational analysis of the transforming growth factor beta receptor type I gene in primary nonsmall cell lung cancer. Lung Cancer 2003, 40(3):28I-287.

8. Zhang HT: Int7G24A variant of the TGFBRI gene and cancer risk: a meta-analysis of three case-control studies. Lung Cancer 2005, 49(3):419-420.

9. Chen T, Jackson C, Costello B, Singer N, Colligan B, Douglass L, Pemberton J, Deddens J, Graff JR, Carter JH: An intronic variant of the TGFBRI gene is associated with carcinomas of the kidney and bladder. Int / Cancer 2004, I I 2(3):420-425.

10. Chen T, Jackson CR, Link A, Markey MP, Colligan BM, Douglass LE, Pemberton JO, Deddens JA, Graff JR, Carter JH: Int7G24A variant of transforming growth factor-beta receptor type $I$ is associated with invasive breast cancer. Clin Cancer Res 2006, I 2(2):392-397.

II. Skoglund Lundin J, Vandrovcova J, Song B, Zhou X, Zelada-Hedman $M$, Werelius $B$, Houlston RS, Lindblom A: TGFBRI variants TGFBRI(*)6A and Int7G24A are not associated with an increased familial colorectal cancer risk. $\mathrm{Br} J$ Cancer 2009, I00(10): 1674-1679.

12. Loktionov A: Common gene polymorphisms, cancer progression and prognosis. Cancer Lett 2004, 208(I): I-33.

13. Slattery ML, Sweeney C, Murtaugh M, Ma KN, Wolff RK, Potter JD, Caan BJ, Samowitz W: Associations between ERalpha, ERbeta, and $A R$ genotypes and colon and rectal cancer. Cancer Epidemiol Biomarkers Prev 2005, I 4( ( 2):2936-2942.

14. Buck MB, Knabbe C: TGF-beta signaling in breast cancer. Ann N Y Acad Sci 2006, 1089: I 19-126.

15. Watson MA, Gay L, Stebbings WS, Speakman CT, Bingham SA, Loktionov A: Apolipoprotein $E$ gene polymorphism and colorectal cancer: gender-specific modulation of risk and prognosis. Clin Sci (Lond) 2003, 104(5):537-545.

16. Bae SJ, Kim JW, Kang H, Hwang SG, Oh D, Kim NK: Gender-specific association between polymorphism of vascular endothelial growth factor (VEGF $936 \mathrm{C}>\mathrm{T}$ ) gene and colon cancer in Korea. Anticancer Res 2008, 28(2B): | 27|- 1276.

17. Press OA, Zhang W, Gordon MA, Yang D, Lurje G, Iqbal S, El-Khoueiry A, Lenz HJ: Gender-related survival differences associated with EGFR polymorphisms in metastatic colon cancer. Cancer Res 2008, 68(8):3037-3042.

18. Wang JM, Irwin RW, Brinton RD: Activation of estrogen receptor alpha increases and estrogen receptor beta decreases apolipoprotein $E$ expression in hippocampus in vitro and in vivo. Proc Natl Acad Sci USA 2006, $103(45)$ : 16983-16988.

19. Ruohola JK, Valve EM, Karkkainen MJ, Joukov V, Alitalo K, Härkönen $\mathrm{PL}$ : Vascular endothelial growth factors are differentially regulated by steroid hormones and antiestrogens in breast cancer cells. Mol Cell Endocrinol I999, I 49( I-2):29-40.

20. Conzen SD: Minireview: nuclear receptors and breast cancer. Mol Endocrinol 2008, 22(10):2215-2228.

21. Marchini J, Cardon LR, Phillips MS, Donnelly P: The effects of human population structure on large genetic association studies. Nat Genet 2004, 36(5):5 I2-5 I7.

22. Pritchard JK, Cox NJ: The allelic architecture of human disease genes: common disease-common variant...or not? Hum $\mathrm{Mol}$ Genet 2002, I I(20):24I7-2423.
23. Markey MP, Graff J, Carter J, Chen T: Alternative splicing of a cancer-associated intronic variant of TGFBRI in cancer cell lines. Proc Amer Assoc Cancer Research 2006, 47:2475.

24. Valle L, Serena-Acedo T, Liyanarachchi S, Hampel H, Comeras I, Li Z, Zeng Q, Zhang HT, Pennison MJ, Sadim M, Pasche B, Tanner SM, de la Chapelle A: Germline allele-specific expression of TGFBR I confers an increased risk of colorectal cancer. Science 2008, 32I(5894): $|36|-1365$.

\section{Pre-publication history}

The pre-publication history for this paper can be accessed here:

http://www.biomedcentral.com/1471-2407/9/406/pre pub
Publish with BioMed Central and every scientist can read your work free of charge

"BioMed Central will be the most significant development for disseminating the results of biomedical research in our lifetime. "

Sir Paul Nurse, Cancer Research UK

Your research papers will be:

- available free of charge to the entire biomedical community

- peer reviewed and published immediately upon acceptance

- cited in PubMed and archived on PubMed Central

- yours - you keep the copyright
BioMedcentral 